Published in final edited form as:

Menopause. 2014 August ; 21(8): 886-889. doi:10.1097/GME.0000000000000190.

\title{
Menopause and benign paroxysmal positional vertigo
}

Oluwaseye Ayoola Ogun, MD1, Bela Büki, MD, PhD², Edward S. Cohn, MD', Kristen L. Janky, AuD, PhD ${ }^{1}$, and Yunxia Wang Lundberg, PhD $^{1, \#}$

${ }^{1}$ Boys Town National Research Hospital, Omaha, NE 68131, USA

${ }^{2}$ Department of Otolaryngology, County Hospital, Krems, Austria

\section{Abstract}

Objective-This study was designed to examine the age and gender distribution and the effect of menopause in a large cohort of participants diagnosed with benign paroxysmal positional vertigo (BPPV).

Methods-We analyzed 1,377 BPPV patients and surveyed 935 women from this group, all diagnosed at Boys Town National Research Hospital (BTNRH) over the last decade.

Results-A detailed age- and gender- distribution analysis of BPPV onset showed that aging had a profound impact on BPPV occurrence in both genders, and that peri-menopausal women were especially susceptible to BPPV (3.2:1 female to male). The latter is a novel finding and was confirmed by a direct survey of female BPPV patients (168 participated). In addition, there was a pronounced female preponderance (6.8:1) for BPPV in the teenage group despite the low prevalence in this age group.

Conclusions-The data suggest that hormonal fluctuations (especially during menopause) may increase the tendency to develop BPPV.

\section{Keywords}

BPPV; epidemiology; aging; menopause; menarche; hormonal fluctuation

\section{Introduction}

The peripheral vestibular organ consists of two accelerometers: the semicircular canals (SCCs) detecting angular velocity changes (i.e., head turning) and the otolithic organs (utricle and saccule) measuring linear accelerations, including gravity (i.e., accelerating in a car or tipping the head forward). In the otolithic organs, otoconia (composite crystals of $\mathrm{CaCO}_{3}$ and proteins) serve as mass load. In benign paroxysmal positional vertigo (BPPV), according to the accepted theory, otoconia dislodge from the utricle and fall into the SCCs, thereby sensitizing them to gravity (Figure 1). In other words, head position changes (lying down, looking up, or turning over in bed) cause short, recurrent vertigo spells. Molecular

\footnotetext{
\#Corresponding author: Yunxia (Yesha) Wang Lundberg, Ph.D. Director, Vestibular Genetics Laboratory, Boys Town National Research Hospital, 555 N. 30th St. Omaha, NE 68131, Ph. 1-402-498-6735 (office), Fax: 1-402-498-6351,

Yesha.Lundberg@boystown.org.

The authors declare no conflict of interest.
} 
causes of BPPV are currently unknown. Most BPPV cases seem to be idiopathic, although some others can be associated with head trauma, vestibular neuritis or concurrent otologic disease (chronic otitis, Meniere's disease, etc). While clinicians have noted more frequent idiopathic cases in the elderly (for review see (1)), few studies have investigated the effects of aging in a large cohort. Based on a telephone interview, Von Brevern et al. (7) estimated the lifetime prevalence of BPPV to be $2.4 \%$, with a gender predisposition towards women (prevalence 3.2\%) compared to men (prevalence 1.6\%) as well as an age-dependence of BPPV, with prevalence steeply rising with age. Likewise, Mizukoshi et al (2) reported a higher ratio of BPPV in females to males with the age at the onset of BPPV peaking in the fourth decade in both genders. Oghalai et al (3) also demonstrated the importance of aging on BPPV occurrence: $9 \%$ of a public, inner-city geriatric population had unrecognized BPPV. These patients were more likely to have reduced activities and to have sustained a fall in the previous three months, highlighting the negative impact of BPPV on daily living. The purpose of this study was to further explore the age and gender distribution and the effect of menopause in a large cohort of patients diagnosed with BPPV.

\section{Materials and Methods}

\section{Study design}

We first reviewed anonymously the age and gender distribution of all patients diagnosed with BPPV at the Vestibular Clinic at Boys Town National Research Hospital (BTNRH) between 2002-2011 $(n=1,377)$. A positive diagnosis of BPPV was the presence of nystagmus (rapid eye movements) elicited in either the Dix-Hallpike or roll maneuver. Although a small subset of patients had subjective BPPV (when patients do not have positional nystagmus, but subjectively report symptoms in response to the Dix-Hallpike maneuver that has a short latency to onset and fatigues with no objective nystagmus) (4), we did not differentiate or exclude subtypes for the current study.

We then directly surveyed female BPPV participants from this group using an anonymous questionnaire, which included current menopausal status, past menstrual cycles and menopausal timing in relation to the onset of BPPV, use of hormone therapy (HT), and history of hysterectomy and oophorectomy. We used the commonly accepted definition of menopause, which is no menses in the previous 12 months. Those diagnosed with other forms of vertigo in addition to BPPV (based on the medical records) were excluded. Out of the 935 female BPPV patients, 168 responded. Among the female survey participants, the ethnicity distribution was 79.9\% "Not Hispanic or Not Latino", and 20.1\% "Hispanic or Latino". The racial distribution was 96.3\% White, 1.2\% African American or Black, 1.8\% Asian and $0.6 \%$ American Indian or Alaskan. Of the participants, $63.4 \%$ live in urban and suburban areas, $33.5 \%$ live in rural areas and $3.1 \%$ were not sure. There were slightly lower percentages of minority races compared those in Nebraska, but given the predominant whites in both populations (there were only 1-3 participants from minority races), such minority differences did not have a significant impact on the conclusion.

BPPV patients from all 4 BTNRH clinics (one in east and one in west Omaha, and one each in two adjacent towns) were included. The size of the general population in the greater Omaha area comprises $2 / 3$ of the total population in Nebraska; therefore, the state's general 
population was used as the comparison group. With regard to oophorectomy (ovariectomy) and hysterectomy, statistics on the USA average were used for comparisons because data on Nebraska population are not available. Such statistics are expected to be similar in Nebraska despite the higher percentages of whites (Hispanic/Latino, black/African American, and Asian in Nebraska are about $60-40 \%$ of the USA average). This is because no significant differences have been found between races in these categories (Keshavarz et al., Surveillance Summaries 2002, http://www.cdc.gov/mmwr/preview/mmwrhtml/ ss5105a1.htm).

All aspects of the study, including the content of the survey and the invitation letter, were reviewed and approved by the Institutional Review Board at BTNRH in accordance with institutional, federal and international guidelines.

\section{Statistical analysis}

Statistical significance of the gender difference among BPPV cases per 100,000 Nebraska population in different age groups was evaluated by $\mathrm{X}^{2}$ analysis with Yates' correction, or by Fisher's exact test when the sample size is small.

\section{Results}

Overall, BPPV prevalence greatly increased with age in both genders when the age-related distribution of the general Nebraska population was considered (Table 1). Across all ages, the female to male ratio was 2.1:1 (935 females: 442 males), falling in the range of previous reports of 1.5 to 2.2:1 (2;5-8). However, BPPV case numbers relative to Nebraska population distributions both pointed to a high female to male ratio in the 40-49 age group at 3.2:1. Interestingly, there was also a high female preponderance for BPPV in the 10-19 age group, with a remarkable female to male ratio of 6.8:1 despite the small number of cases (Table 1). An anonymous review of BPPV cases at BTNRH from an earlier time period (1998-2007) also showed similar high female to male ratios of 3.3:1 and 8.4:1, respectively, in these age groups.

A direct survey of the female BPPV patients $(n=168)$ showed that $48.1 \%$ experienced their first episodes of BPPV after menopause (14.7\% of the 40-49 year-olds are postmenopausal), with only $9.0 \%$ on hormone therapy (HT). Among the women survey participants, $22.4 \%$ had oophorectomy (ovariectomy) and 32.0\% had hysterectomy. In the general USA population, about $0.2 \%$ women receive oophorectomy and $0.5 \%$ receive hysterectomy (9), and about $40 \%$ of all postmenopausal women in the USA have ever used HT (nearly $50 \%$ of HT use based on the CDC 2001 report by Brett and Chong at www.cdc.gov/nchs/data/misc/ hrt_booklet.PDF, with an approximate 20\% decline of HT prescriptions since 2006 at http:// www.menopause.org/publications/clinical-practice-materials/Htstatistics). For reasons stated in the Method section, the general Nebraska population likely have statistics similar to the USA average, except for a possible higher percentage of HT use because non-Hispanic white women are more likely to use HT (also Brett and Chong). Compared to the entire BPPV population from BTNRH, there were fewer participants in the 70+ groups, but similar distribution in other age groups, so the possible age bias does not affect the main conclusion. 


\section{Discussion}

BPPV is not only common, but also incapacitating, especially in the elderly. It can induce nausea, vomiting, fear, and balance dysfunction, which severely interferes with activities of daily living such as walking and driving, predisposing an individual to injury, hospitalization and isolation. Our data show that age and gender are critical factors influencing BPPV onset with an increase in prevalence with age in both genders and a significant female preponderance. The even greater female to male ratio of BPPV cases in the 10-19 and 40-49 age groups are novel findings and suggest that hormonal fluctuations, whether in increase or decline, may influence BPPV occurrence.

Among the general USA population, the average age of menopause is $51(10 ; 11)$ and the average age of menarche is 12.5 (12). In women, estrogen and progesterone begin to decline before menopause, and remain low after menopause, while follicle-stimulating hormone (FSH) rises and remains high. Perimenopausal fluctuations of estrogen levels, not just low estrogen levels, may account for the increased BPPV susceptibility of 40-49 year-old women. This is also reflected in the high rate of oophorectomy in these women who likely experienced acute changes in hormone levels. Nevertheless, the higher BPPV prevalence in older women suggests that low estrogen levels do affect BPPV onset. In men, androgens (e.g. testosterone) and estrogen also decline during this age period, but at a much slower rate. While age effects on BPPV onset have been noted by previous reports $(6 ; 13)$, the differential effects of aging in different genders have not been previously reported, nor has a detailed age and gender distribution of BPPV occurrence.

Although formed at embryonic stages, mammalian otoconia appear to require proper maintenance during adult life, because aging leads to otoconia degeneration in both humans (14-16) and animals (17-19). As observed by these studies, age-related changes in the microenvironment and fragility of anchoring protein filaments (keeping otoconia adhered in the otolith organs) would induce deterioration and dislocation. In addition, since $\mathrm{Ca}^{2+}$ in otoconia is extruded by vestibular hair cells (20), it is tempting to speculate that otoconial degeneration can also be associated with hair cell loss seen in the elderly (21). Other types of age-related vestibular neurosensory degeneration can facilitate BPPV onset as well (22). In addition, aging disrupts the homeostasis of endolymphatic ions and anions (23), which would affect otoconia. Because a great majority (about $90 \%$ or higher) of recurring BPPV cases are unilateral (24) and because particle repositioning maneuvers (specific head maneuvers designed to return the dislocated otoconia from the semicircular canals back to the utricle) are largely effective in most cases, at least for a period of time, otoconia-related abnormalities are more likely to be the primary cause.

While molecular events during aging to cause BPPV are unknown, in animal studies, numerous proteins important for otoconia formation and maintenance are no longer expressed or are only expressed at very low levels beyond early to mid-adulthood, and estrogen deficiency exacerbates such problems (Xu, Yang and Lundberg, unpublished data). Therefore, as part of the natural aging process, estrogen decline may cause otoconia degeneration and dislocation. Indeed, ovariectomy affects otoconia maintenance in rats (25) and mice (Yang, Xu and Lundberg, unpublished data). Although Vibert et al., (25) did not 
address whether otoconia in ovariectomized rats become dislocated more easily, an ongoing study in our lab shows that this is the case in ovariectomized mice (Yang, Xu and Lundberg, unpublished data). Based on published information regarding the effects of estrogen and its receptors on the inner ear, mostly on the cochlea, estrogen may also influence endolymph ionic and anionic homeostasis through regulating expression of ion and anion channels and pumps $(26 ; 27)$. Endolymphatic ions and anions are known to influence otoconia/otolith formation in mice and fish [reviewed in (28) and may be an additional mechanism underlying the influence of estrogen on otoconia maintenance and anchoring. It is possible that either a sudden drop or rise in estrogen would disrupt anion/ion homeostasis as well as affect neurosensory function, thereby contributing to the higher BPPV prevalence in older women and even young women entering puberty.

Although using only one BPPV population from a single hospital and its affiliated clinics has some advantages, such as uniform diagnostic criteria, it could have some potential limitations. For example, cases in the general population which are undiagnosed, or simply not diagnosed at our hospital, are not included. However, based on previous studies (references throughout Introduction and Result) and the location and specialty (primarily otolaryngology and pediatrics) of our hospital and clinics, the higher prevalence of BPPV in women and older people cannot be simply attributed to the fact that more women or older people see a doctor. Also, the obtained prevalence is based on per 100,000 NE population, and older men (60 and over) actually have higher prevalence relative to females when compared with the gender ratios of other age groups, so our overall conclusion is not likely a sampling bias.

\section{Conclusion}

Our data suggest important effects of age and gender on BPPV onset, which may be partly attributed to hormonal fluctuations in the etiology. Based on otoconia studies in aging animals, we propose that otoconia degeneration, exacerbated by estrogen deficiency, may underlie such effects in older people and is an important area for further research.

\section{Acknowledgments}

This work was supported by grants from the National Institutes of Health, R01DC008603, R01DC008603-S1 and P20GM103471 (formerly P20RR018788) pilot funding to Y.W.L., postdoctoral training grant T32DC000013 to O.A.O., P20GM103471 pilot funding to E.S.C., and institutional support from BTNRH. We thank Walt Jesteadt for his feedback on the manuscript, Susan J. Grennan for her help with the diagnostic review of medical records, and Rebecca Cash for her help with the IRB application process.

\section{Reference List}

1. Parnes LS, Agrawal SK, Atlas J. Diagnosis and management of benign paroxysmal positional vertigo (BPPV). CMAJ. 2003 Sep 30; 169(7):681-93. [PubMed: 14517129]

2. Mizukoshi K, Watanabe Y, Shojaku H, Okubo J, Watanabe I. Epidemiological studies on benign paroxysmal positional vertigo in Japan. Acta Otolaryngol.Suppl. 1988; 447:67-72. [PubMed: 3188895]

3. Oghalai JS, Manolidis S, Barth JL, Stewart MG, Jenkins HA. Unrecognized benign paroxysmal positional vertigo in elderly patients. Otolaryngol Head Neck Surg. 2000 May; 122(5):630-4. [PubMed: 10793337] 
4. Buki B, Simon L, Garab S, Lundberg YW, Junger H, Straumann D. Sitting-up vertigo and trunk retropulsion in patients with benign positional vertigo but without positional nystagmus. J Neurol Neurosurg Psychiatry. 2011 Jan; 82(1):98-104. [PubMed: 20660923]

5. Katsarkas A. Benign paroxysmal positional vertigo (BPPV): idiopathic versus post-traumatic. Acta Otolaryngol. 1999; 119(7):745-9. [PubMed: 10687929]

6. Salvinelli F, Firrisi L, Casale M, Trivelli M, D'Ascanio L, Lamanna F, Greco F, Costantino S. Benign paroxysmal positional vertigo: diagnosis and treatment. Clin Ter. 2004 Sep; 155(9):395400. [PubMed: 15700633]

7. Von Brevern M, Radtke A, Lezius F, Feldmann M, Ziese T, Lempert T, Neuhauser H. Epidemiology of benign paroxysmal positional vertigo: a population based study. J Neurol Neurosurg Psychiatry. 2007 Jul; 78(7):710-5. [PubMed: 17135456]

8. Zhang Y, Chen X, Wang X, Cao L, Dong Z, Zhen J, Li G, Zhao Z. A clinical epidemiological study in 187 patients with vertigo. Cell Biochem Biophys. 2011 Mar; 59(2):109-12. [PubMed: 20976571]

9. Keshavarz H, Hillis SD, Kieke BA, Marchbanks PA. Hysterectomy Surveillance---United States, 1994--1999. MMWR CDC Surveill Summ. 2002 Jul 12; 51(5):1-8.

10. Henderson KD, Bernstein L, Henderson B, Kolonel L, Pike MC. Predictors of the timing of natural menopause in the Multiethnic Cohort Study. Am J Epidemiol. 2008 Jun 1; 167(11):1287-94. [PubMed: 18359953]

11. Nelson HD. Menopause. Lancet. 2008 Mar 1; 371(9614):760-70. [PubMed: 18313505]

12. Anderson SE, Dallal GE, Must A. Relative weight and race influence average age at menarche: results from two nationally representative surveys of US girls studied 25 years apart. Pediatrics. 2003 Apr; 111(4 Pt 1):844-50. [PubMed: 12671122]

13. Baloh RW, Honrubia V, Jacobson K. Benign positional vertigo: clinical and oculographic features in 240 cases. Neurology. 1987 Mar; 37(3):371-8. [PubMed: 3822129]

14. Anniko M, Ylikoski J, Wroblewski R. Microprobe analysis of human otoconia. Acta Otolaryngol. 1984 Mar; 97(3-4):283-9. [PubMed: 6720304]

15. Igarashi M, Saito R, Mizukoshi K, Alford BR. Otoconia in young and elderly persons: a temporal bone study. Acta Otolaryngol.Suppl. 1993; 504:26-9. [PubMed: 8470528]

16. Ross MD, Peacor D, Johnsson LG, Allard LF. Observations on normal and degenerating human otoconia. Ann Otol Rhinol Laryngol. 1976 May; 85(3 pt 1):310-26. [PubMed: 937958]

17. Jang YS, Hwang CH, Shin JY, Bae WY, Kim LS. Age-related changes on the morphology of the otoconia. Laryngoscope. 2006 Jun; 116(6):996-1001. [PubMed: 16735917]

18. Lim DJ. Otoconia in health and disease. A review. Ann Otol Rhinol Laryngol.Suppl. 1984 Jul. 112:17-24. [PubMed: 6431876]

19. Takumida M, Zhang DM. Electron probe X-ray microanalysis of otoconia in guinea pig inner ear: a comparison between young and old animals. Acta Otolaryngol. 1997 Jul; 117(4):529-37. [PubMed: 9288208]

20. Kozel PJ, Friedman RA, Erway LC, Yamoah EN, Liu LH, Riddle T, Duffy JJ, Doetschman T, Miller ML, Cardell EL, et al. Balance and hearing deficits in mice with a null mutation in the gene encoding plasma membrane Ca2+-ATPase isoform 2. J Biol Chem. 1998 Jul 24; 273(30):18693-6. [PubMed: 9668038]

21. Merchant SN, Velazquez-Villasenor L, Tsuji K, Glynn RJ, Wall C III, Rauch SD. Temporal bone studies of the human peripheral vestibular system. Normative vestibular hair cell data. Ann Otol Rhinol Laryngol.Suppl. 2000 May.181:3-13. [PubMed: 10821229]

22. Gacek RR. Pathology of benign paroxysmal positional vertigo revisited. Ann Otol Rhinol Laryngol. 2003 Jul; 112(7):574-82. [PubMed: 12903676]

23. Gratton MA, Smyth BJ, Lam CF, Boettcher FA, Schmiedt RA. Decline in the endocochlear potential corresponds to decreased $\mathrm{Na}, \mathrm{K}$-ATPase activity in the lateral wall of quiet-aged gerbils. Hear Res. 1997 Jun; 108(1-2):9-16. [PubMed: 9213117]

24. Soto-Varela A, Rossi-Izquierdo M, Santos-Perez S. Benign paroxysmal positional vertigo simultaneously affecting several canals: a 46-patient series. Eur Arch Otorhinolaryngol. 2013 Mar; 270(3):817-22. [PubMed: 22566181] 
25. Vibert D, Sans A, Kompis M, Travo C, Muhlbauer RC, Tschudi I, Boukhaddaoui H, Hausler R. Ultrastructural changes in otoconia of osteoporotic rats. Audiol Neurootol. 2008; 13(5):293-301. [PubMed: 18391565]

26. Chen J, Nathans J. Estrogen-related receptor beta/NR3B2 controls epithelial cell fate and endolymph production by the stria vascularis. Dev Cell. 2007 Sep; 13(3):325-37. [PubMed: 17765677]

27. Lee JH, Marcus DC. Estrogen acutely inhibits ion transport by isolated stria vascularis. Hear Res. 2001 Aug; 158(1-2):123-30. [PubMed: 11506944]

28. Lundberg, YW.; Xu, Y. Proteins Involved in Otoconia Formation and Maintenance. In: Gendeh, BalwantSingh, editor. Otolaryngology. In Tech; 2012. p. 3-22.

29. 2010 Demographic Profile Data - Nebraska U. S. Census Bureau. 2010. http:// factfinder2.census.gov/faces/tableservices/jsf/pages/productview.xhtml? src=bkmk: www.census.gov 

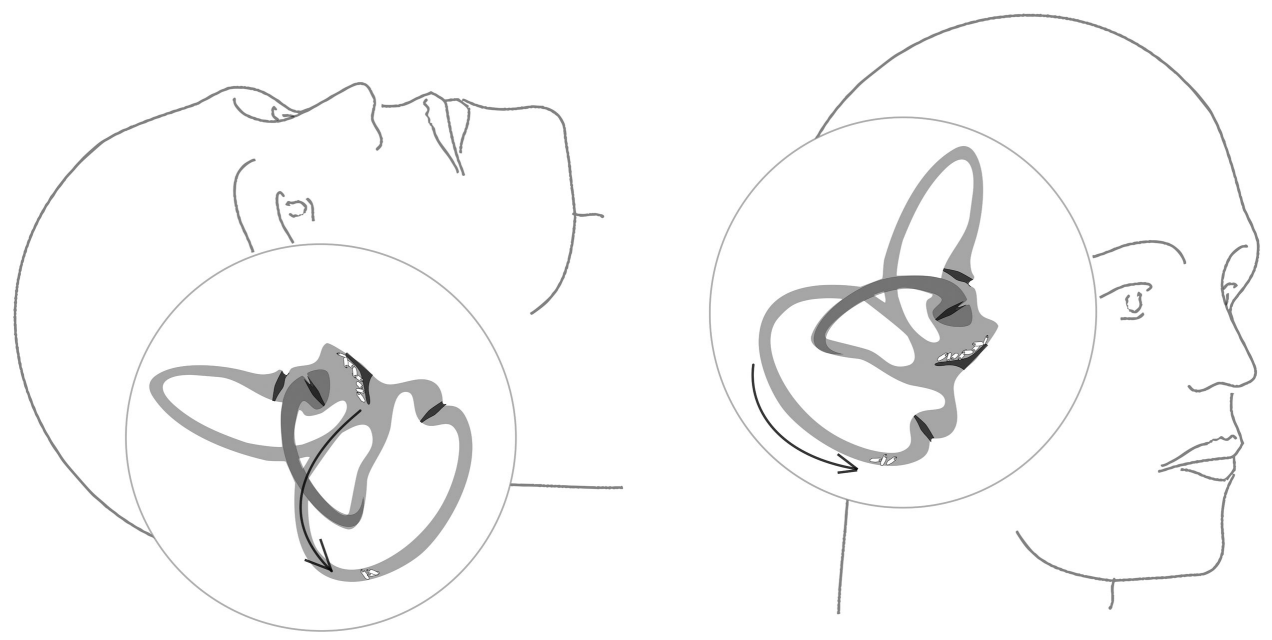

Figure 1.

Otoconia movements in BPPV. (Left) During night rest, otoconia fall from the utricular macula into the semicircular canal (arrow). (Right) During sitting up, movement of otoconia in the canal causes abnormal endolymph motion and vertigo. 


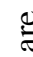

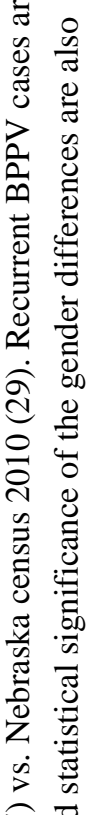

尺 